\title{
Pharmaceutical Review
}

ISSN 2220-5187, Constituted by Pharmacist Federation

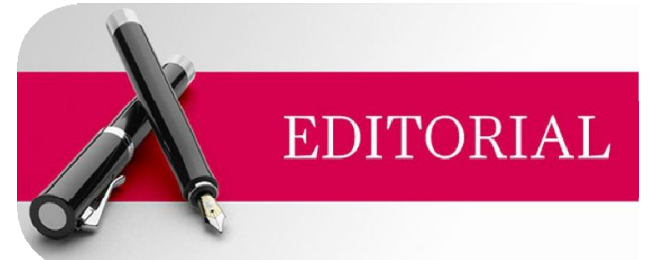

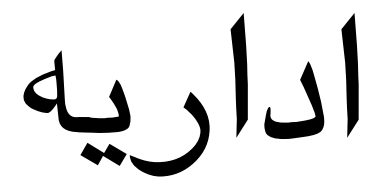

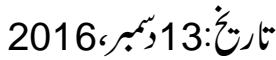

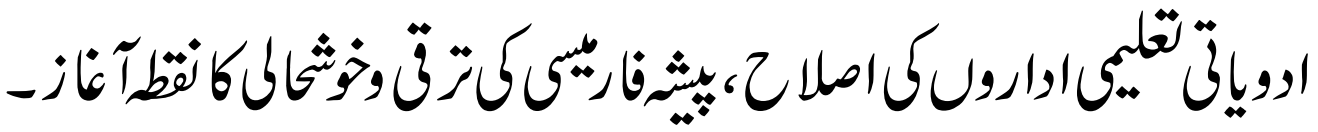

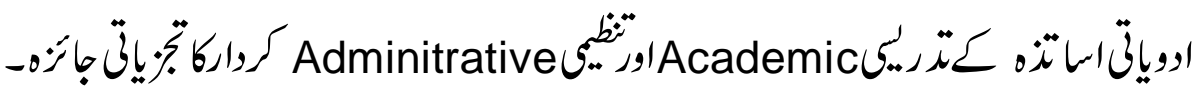

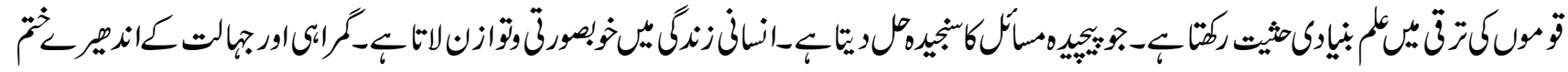

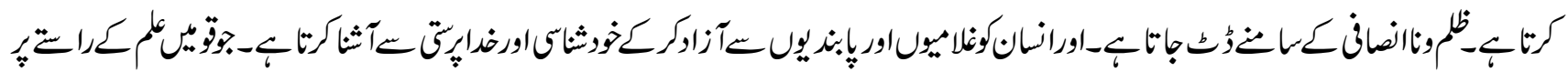

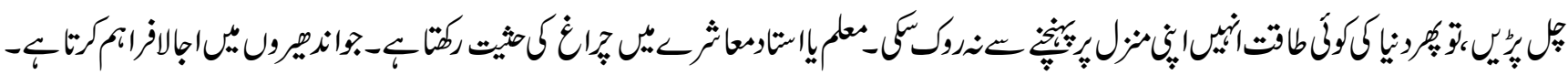

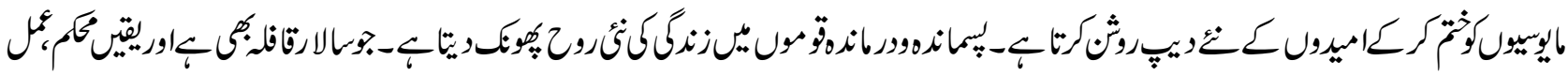

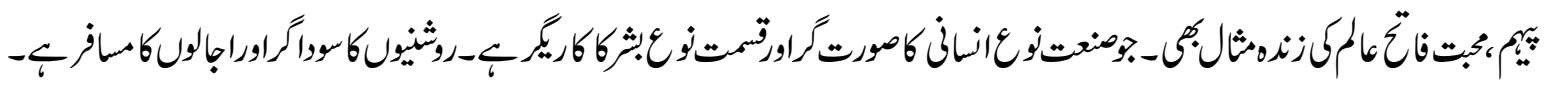

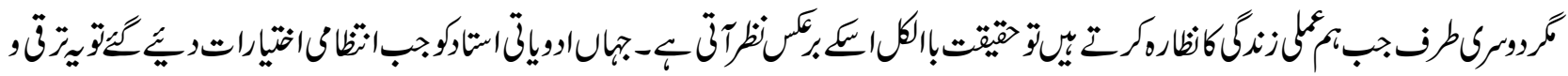

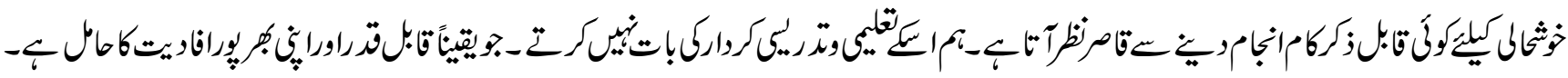

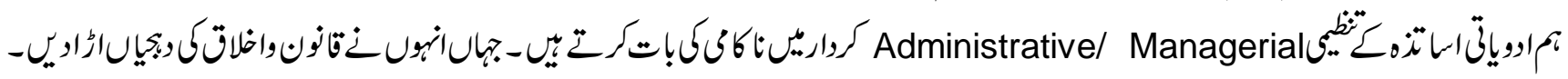

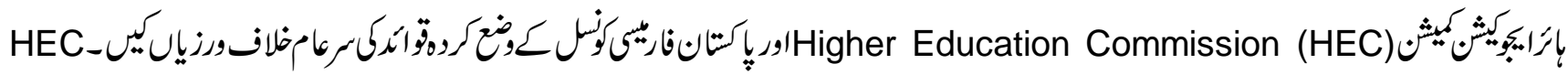

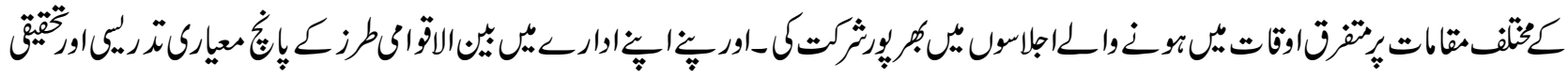

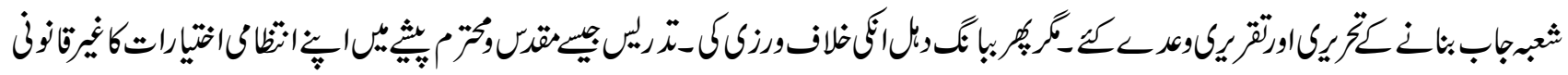

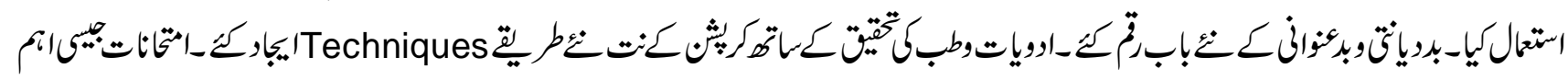

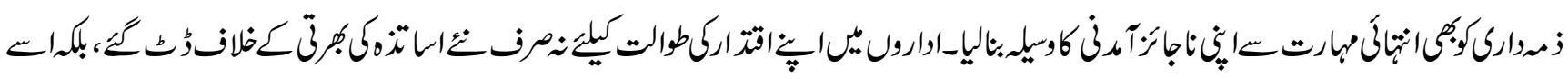

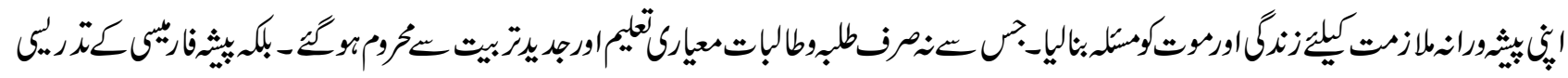

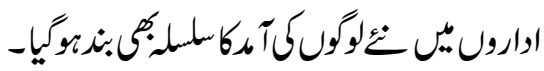

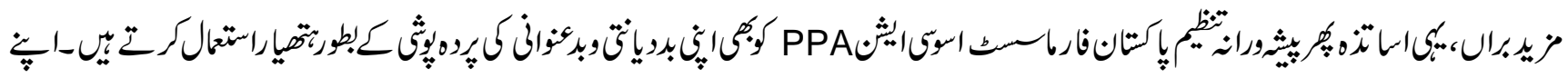

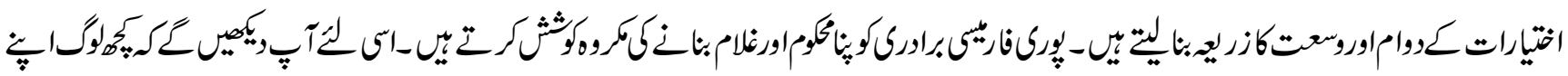

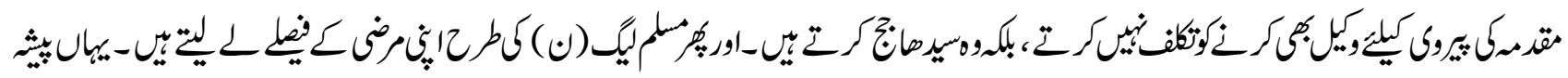




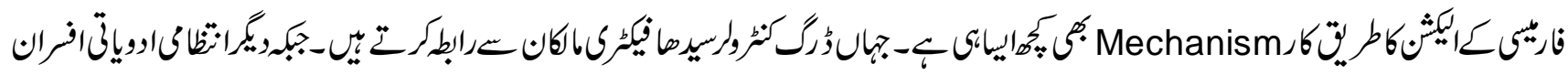

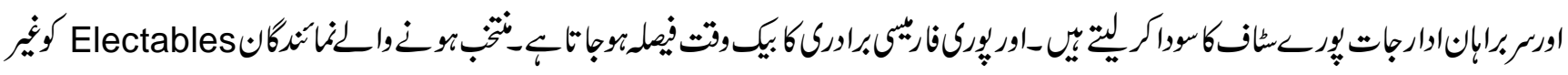

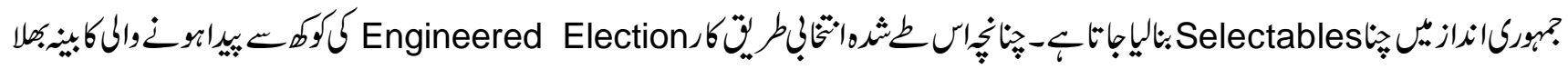

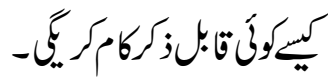

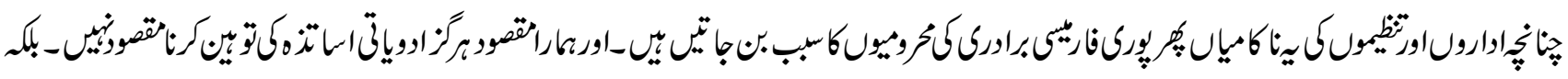

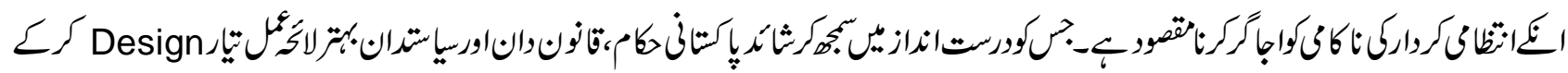

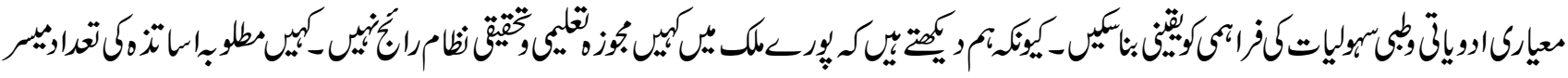

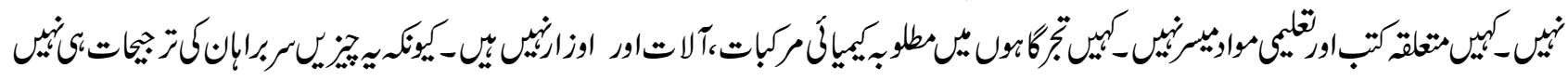

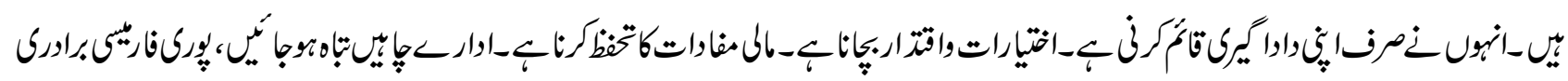

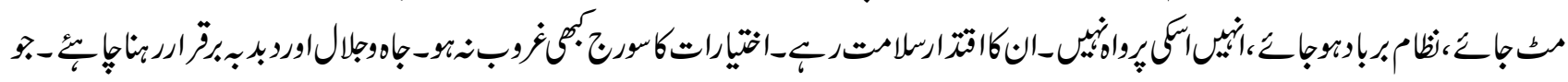

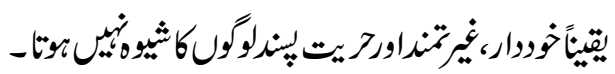

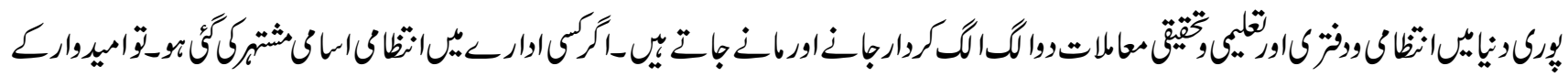

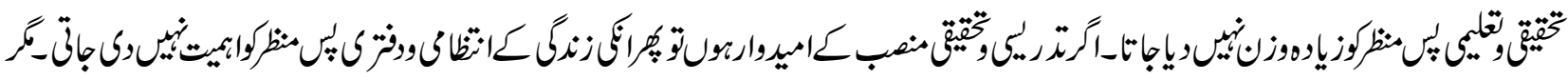

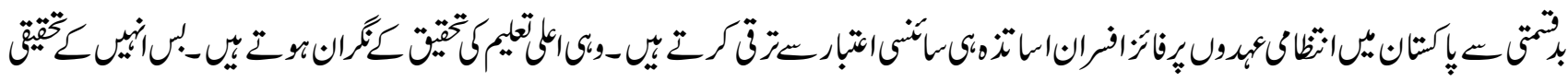

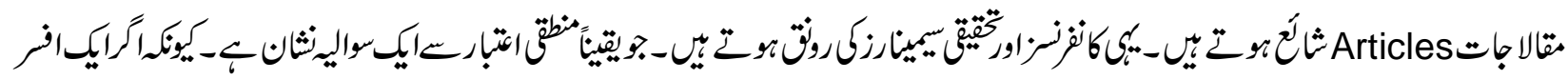

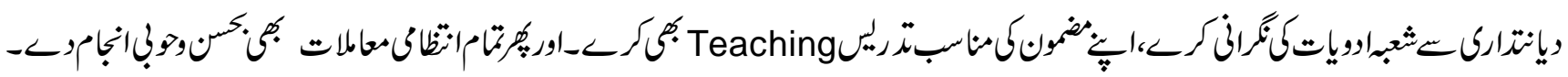

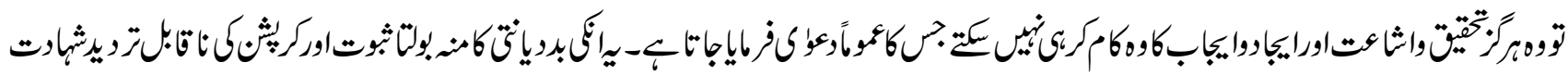

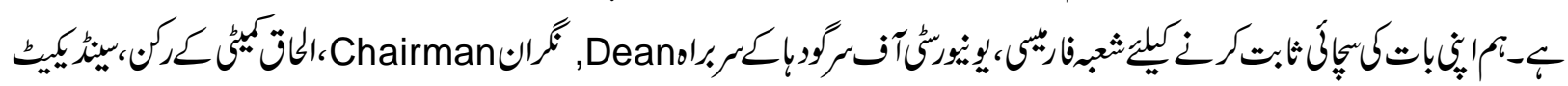

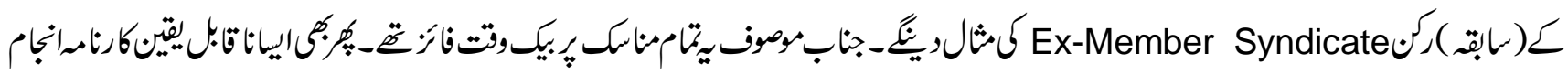

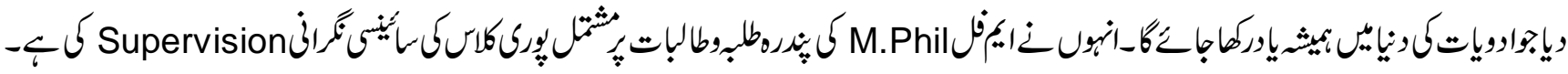

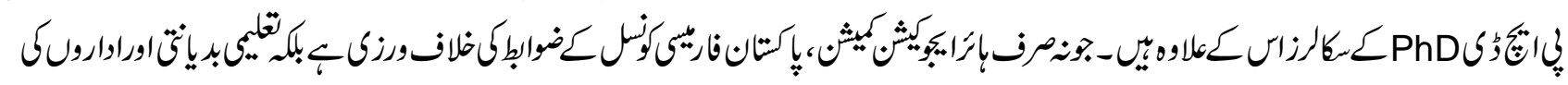

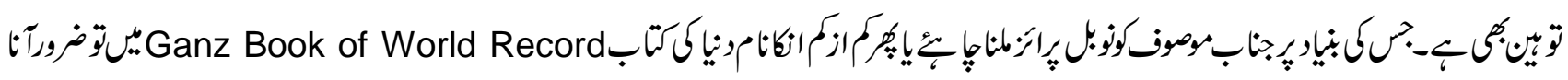

تهن

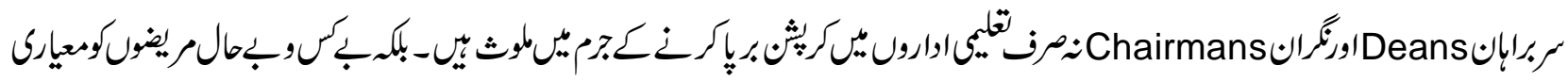

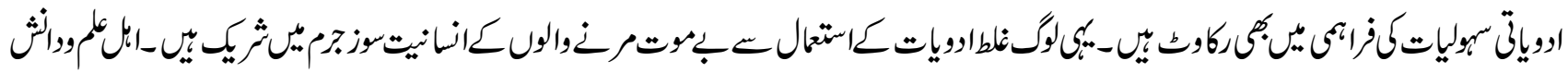

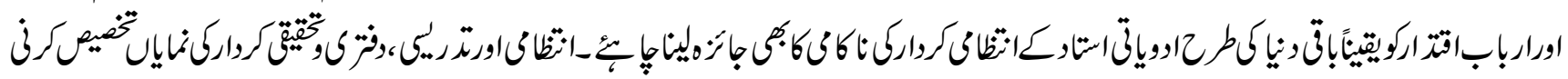

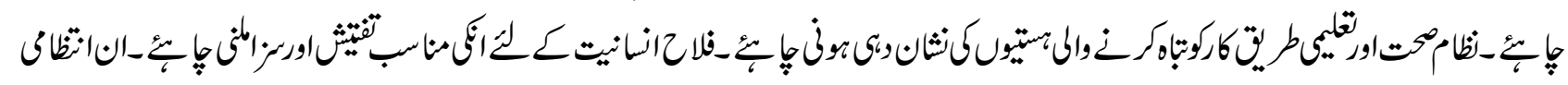




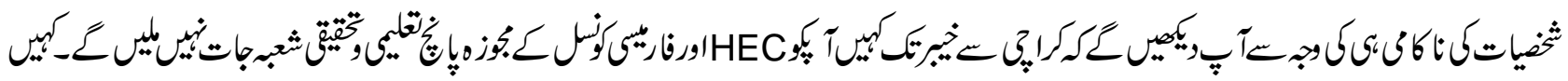

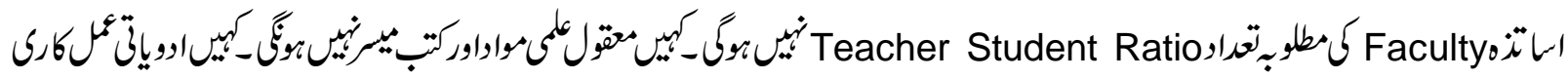
'Subscription of research datarmacy Practice

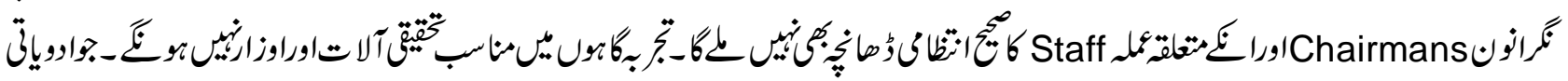

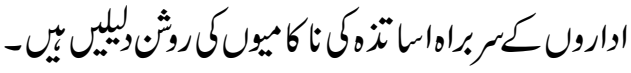

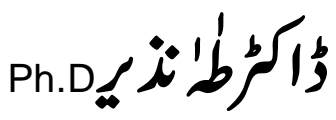

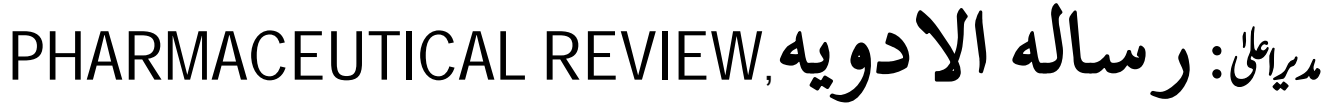

ISSN: 2220-5187; W.: http://pharmarev.com/

C.: +92 321222 0885, E.: tahanazir@yahoo.com 